\title{
Impact of demand controlled ventilation on system performance and energy use
}

\author{
Muhannad Delwati $^{\mathrm{a}, \mathrm{d}, *}$, Bart Merema $^{\mathrm{b}}$, Hilde Breesch ${ }^{\mathrm{b}}$, Lieve Helsen ${ }^{\mathrm{a}, \mathrm{c}}$, Maarten Sourbron $^{\mathrm{a}}$ \\ a Department of Mechanical Engineering, KU Leuven, Celestijnenlaan 300 , Leuven 3001, Belgium \\ ${ }^{\mathrm{b}}$ Department of Civil Engineering, Construction Technology Cluster, KU Leuven, Ghent, Belgium \\ ${ }^{\mathrm{c}}$ EnergyVille, Thor Park, Waterschei, Genk, Belgium \\ d Department of Architecture, KU Leuven, Leuven, Belgium
}

\section{A R T I C L E I N F O}

\section{Article history:}

Received 30 December 2017

Revised 17 June 2018

Accepted 17 June 2018

Available online 28 June 2018

\section{Keywords:}

Demand controlled ventilation

Ventilation system performance

Fan energy use

Pressure set point

Control strategies

Trim \& respond

\begin{abstract}
A B S T R A C T
Demand-controlled-ventilation (DCV) refers to a ventilation system with controlled air flow rate based on indoor air quality. DCV operates at reduced air flow rates during most of the operation time. Therefore, less energy is required for fan operation, compared to a constant-air-volume (CAV) ventilation system.

Typically, DCV has a two-layer control with variable-air-volume (VAV) valves, and a fan speed control to maintain a constant-static-pressure in the duct system based on a pressure set point.

However, this nominal design based fan pressure setpoint is higher than required when all VAV-valves are closed to a certain extent. Therefore, advanced pressure-reset (PR) control - resetting the pressure set point - potentially reduces fan energy use even further.

This paper assesses the impact of fan control on both fan energy use and ventilation performance in DCV system of a densely occupied office. Results of a simulation model and realistic measurement setup are compared. The PR control, using air flow rate and VAV-valve position measurements as feedback, causes significantly reduction on fan energy use. These reductions compared to conventional DCV and CAV respectively, are approximately $10 \%$ and $72 \%$ in case of high occupancy and $50 \%$ and $93 \%$ in case of low occupancy. Largely, DCV with PR control is strongly considered, especially when occupancy is often expected to deviate significantly from the nominal conditions. Moreover, both simulations and measurements show that there is a clear trade-off between air flow rate deficit and fan energy use, when the fan energy use is lower, the air flow rate deficit is higher and vice versa. Furthermore, the results show that VAV-valve accuracy, characteristics and its lower operational limit hamper the ventilation system in achieving the predicted performance as in the simulation.
\end{abstract}

(c) 2018 Elsevier B.V. All rights reserved.

\section{Introduction}

Requirements on building system efficiency are getting more stringent. A next step after improving the energy performance of the building envelope, i.e. the insulation level and airtightness, is the quest towards more efficient heating, cooling and ventilation systems. In this, ventilation energy use is essential, with shares of $10-50 \%$ of a building's electricity consumption [1]. De-

Abbreviations: DCV, Demand-controlled-ventilation; CAV, Constant air volume; VAV, Variable air volume; PR control, Pressure reset control; RMSE, Root mean square error; PI controller, Proportional integral controller; CPSP, Constant static pressure set point; VPSP, Variable static pressure set point; AFD, Air flow rate deficit; AFS, Air flow rate surplus.

* Corresponding author at: Department of Architecture, KU Leuven, Kasteelpark Arenberg 1, Leuven 3001, Belgium.

E-mail address: Muhannad.delwati@kuleuven.be (M. Delwati). mand Controlled Ventilation (DCV), being 'a ventilation system with feedback or feedforward control of air volume flows based on an indoor air quality indicator' [2], has a large potential to reduce this ventilation energy demand for electricity, and also for thermal and humidity control of the supplied air. Braun et al. [3] identified DCV with heat recovery as the best technology for energy and cost savings. Wachenfeldt et al. [4] calculated savings of $87 \%$ on fan energy and $21 \%$ on heating energy for two Norwegian schools. while Ahmed et al. [5] showed a decrease of $33-41 \%$ of the energy needed for heating, cooling and fans in an office building.

With DCV, in a first zone control level, the control agent is a variable air volume (VAV) valve that reacts to a room parameter $\left(\mathrm{CO}_{2}\right.$, temperature, humidity or a combination) by adapting the air flow rate towards the zone as shown in Fig. 1. In a second fan control level, the fan variable speed drive is the control agent, which reacts to a feedback signal from the ventilation system (duct static 


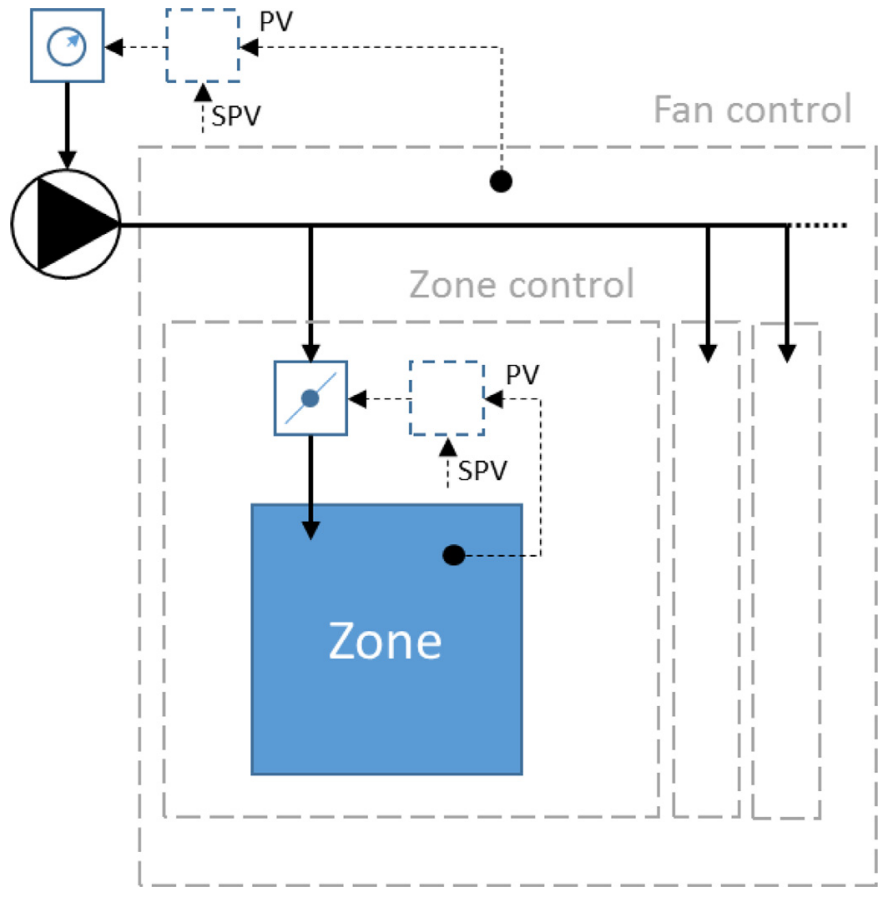

Fig. 1. Zone and fan control level in standard DCV systems (PV: measured process value, SPV: set point value).

pressure, required air flow rate). If one of the VAV-valves closes as a result of the decrease of the required air flow rate in the ventilated zone, the pressure loss in this terminal will increase. As a consequence, the duct static pressure will increase. To keep the measured duct static pressure at its set point, the supply fan reduces its speed according to the deviation between the measured and the set point value. To produce the required air flow rate in the duct branches at the highest pressure drop in DCV systems, the fan speed is typically controlled to maintain a constant static pressure set point in the duct system, based on the critical design full load conditions.

In practice, the ventilation system load varies according to occupancy. However, the ventilation system works with the nominal design based pressure set point even in partial load. This results in a duct static pressure and fan energy use that are higher than necessary.

To solve this problem, a pressure reset (PR) control strategy is typically implemented so the fan static pressure set point is reset, based on the required air flow rate and/or VAV-valve position. Several practical implementations of this control are described by various authors [6-9]. The main idea behind this PR-control is to keep VAV-valves position as fully open as possible to minimise the pressure loss in the valve unit.

In the standard control strategy, static pressure set point is calculated according to the required static pressure, which can deliver the design flow to the most critical zone under nominal conditions [8-9].

When all VAV-valves are closed to a certain extent, the logic of the static pressure reset algorithm is to reduce the static pressure set point until at least one of the VAV-valves is (almost) open. Reversely, when all VAV-valves open, the static pressure set point is increased to keep valve authority. The air flow rate increases and the VAV controller reacts to maintain the air flow rate set point so it closes the VAV-valve, until only one VAV-valve is (almost) open. When at least one VAV-valve gets open, the static pressure set point is increased. This cycle of checking VAV-valve positions and adapting the static pressure set point is continuously repeated
[6] and is referred to as the 'Trim-and-Respond' method. The fan trims the duct static pressure, and as result VAV-valves respond both measured VAV-valve positions and air flow rates to the PRcontrol as described in Fig. 2.

None of the previous studies assess the trim and respond method with respect to energy use and ventilation performance. Moreover, they did not discuss the sensitivity of the control parameters which define the value of increasing or decreasing the pressure set point.

The main aim of this study is to compare the impact of different DCV fan control strategies with respect to energy use and ventilation performance. Moreover, this study aims to assess the control parameters' sensitivity with respect to the air comfort conditions in the ventilated zones.

In this paper, an aerolic Modelica [10] 3-zone DCV system model for a densely occupied office zone is set up to compare the impact of the DCV control strategies regarding to the ventilation performance and fan energy use. A full scale laboratory test setup representing this 3 zones ventilation system is used to validate the DCV system Modelica model. In the Methodology section the ventilation system, the lab setup, the simulation model, the investigated control strategies and the evaluation procedure are described. The Results and Discussion section presents the validation of the simulation model and an analysis of the effect of the investigated control strategies. The Conclusions section summarizes this work and presents guidelines for designers.

\section{Methodology}

\subsection{3 zones office ventilation system test case}

The supply part of a ventilation system for 3 densely occupied landscaped office zones is investigated as shown in Fig. 3. It is assumed that each zone has a floor area of $100 \mathrm{~m}^{2}$ and can accommodate 12 people $\left(8.3 \mathrm{~m}^{2} /\right.$ pers $)$. The required air flow rate is (8) l/s.pers, or (28.8) $\mathrm{m}^{3} / \mathrm{h}$.pers [13], leading to $1036 \mathrm{~m}^{3} / \mathrm{h}$ in total for the 3 zones.

\subsection{Ventilation system lab setup}

The lab test system represents the ventilation system as shown in Fig. 5, for the 3 landscaped office zones. The lab installation has a main duct and 3 branches inside a lab space of $4 \times 3 \times 2.5 \mathrm{~m}^{3}$.

The ducts lengths in the main line are replaced by iris dampers to represent an equal pressure drop corresponding to the design conditions as shown in Fig. 4. The same system is modelled in the simulation model.

It is important to notice that in the lab setup, due to the absence of an occupied zone, the VAV-valves are not controlled by a PI-controller operating on a measured $\mathrm{CO}_{2}$-value in the zone, but directly on a required air flow rate set point, which is addressed in the 'Air flow rate profiles' section (Figs. 9 and 10). This approach was chosen because, for validation purposes, an equivalent system in the simulation environment and as well in lab setup is needed.

The static pressure sensor is located in the main duct at $2 / 3$ of the distance along the main duct [7], to avoid measuring the swirling flow directly after the fan. The pressure sensor position is indicated on Fig. 4.

The duct system is designed using the static regain method [11]. This design method is preferred because an energy saving potential of almost $17 \%$ was obtained, compared to both equal-friction and velocity reduction methods, due to larger duct sizes and automatic balancing. The ducts have a diameter of $250 \mathrm{~mm}$ in the main line A-B and $200 \mathrm{~mm}$ for the branch lines B-E, C-F and D-G as shown 

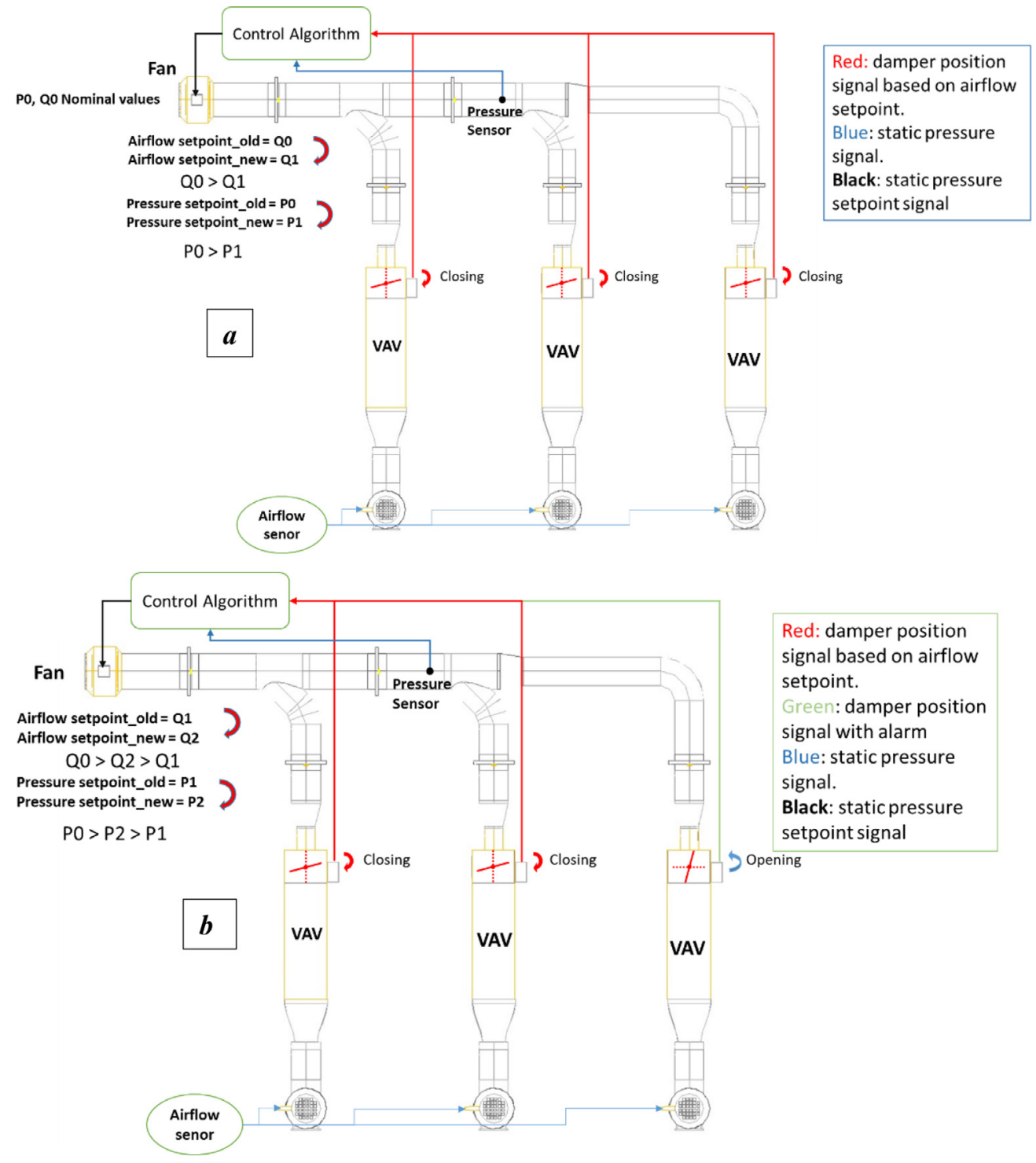

Red: damper position signal based on airflow setpoint.

Green: damper position signal with alarm Blue: static pressure signal.

Black: static pressure setpoint signal

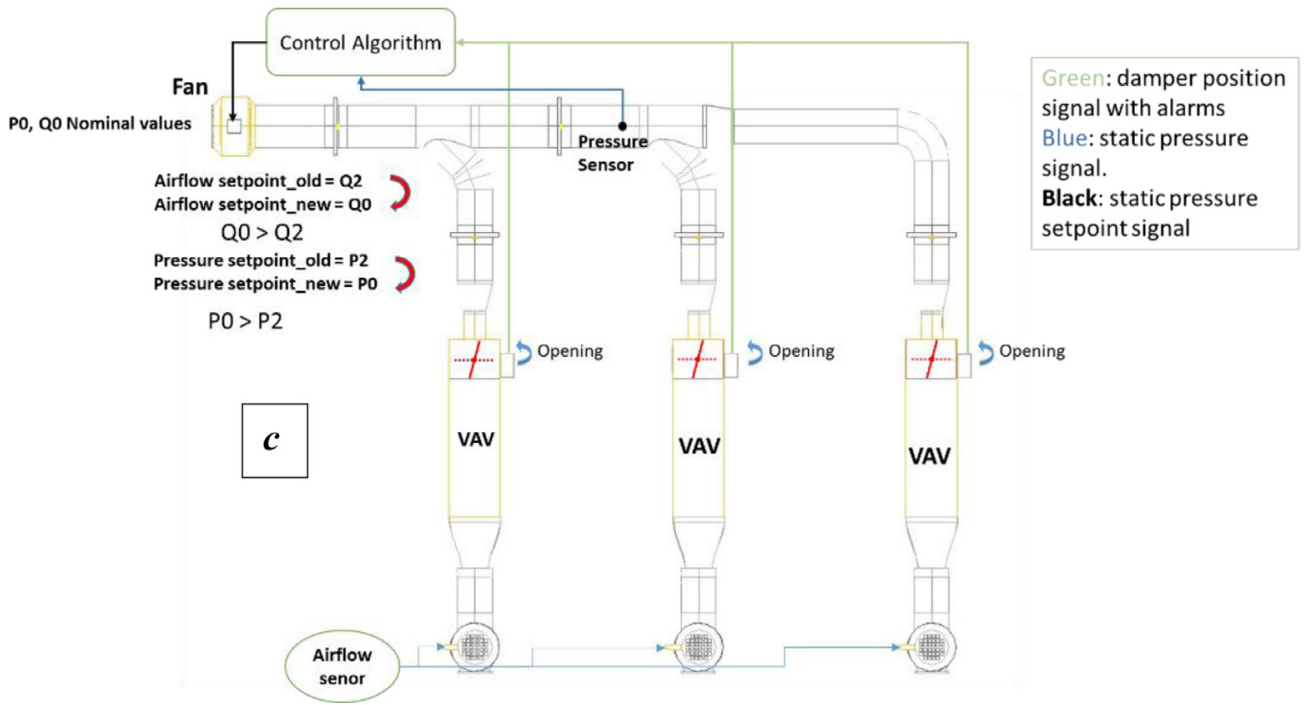

Fig. 2. Systematic schemes of the PR control algorithm from a to c. 


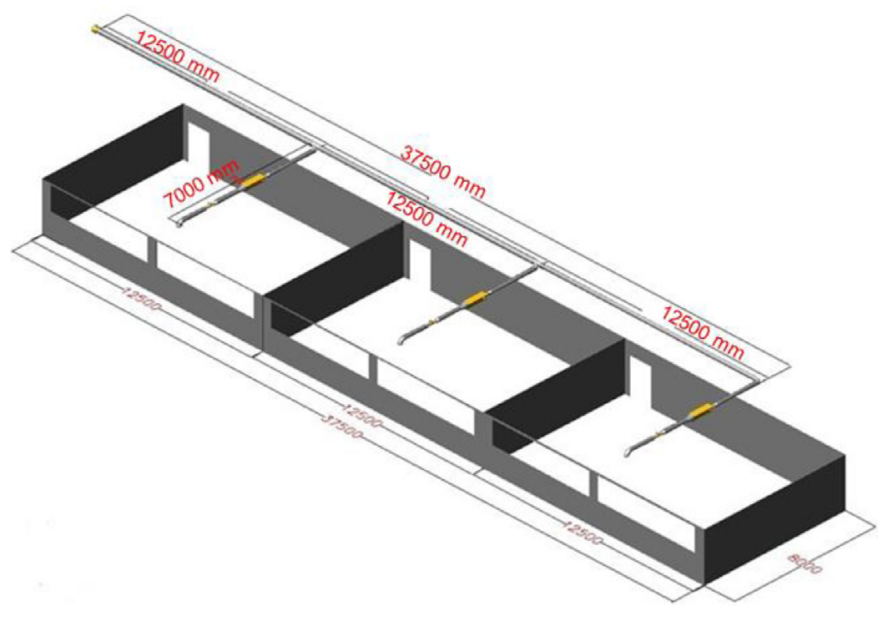

Fig. 3. 3D-view of the ventilation system for 3 office zones.

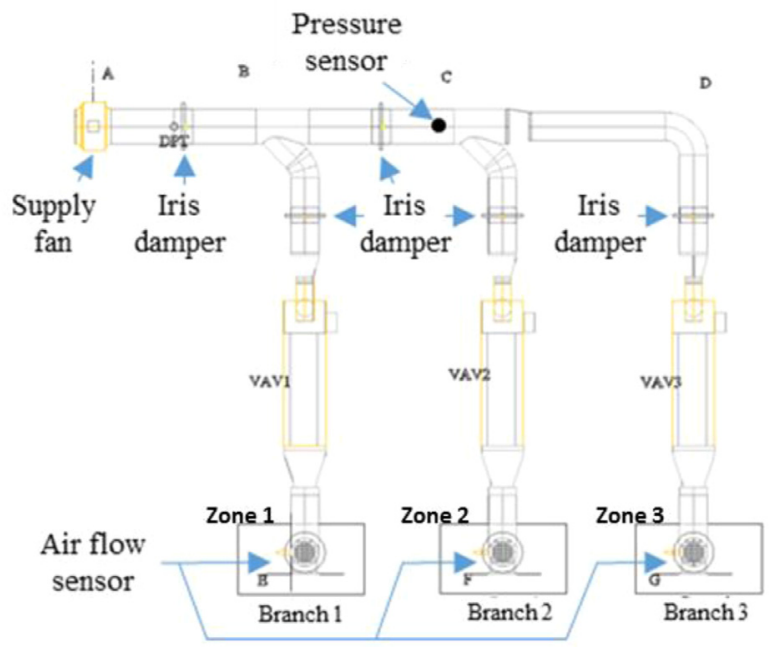

Fig. 4. schematic view of lab setup of ventilation system for the 3 office zones.

on Fig. 4. The VAV-boxes have an inlet diameter of $125 \mathrm{~mm}$. A central axial fan supplies air to the main duct, and the fan speed is controlled with an integrated PI-controller reacting to a $0-10 \mathrm{~V}$ signal.
Air flow rate is measured by commercial air volume flow rate measuring units (Trox VMR diam. 125), installed at the end of each terminal line as shown in Figs. 4 and 5. They measure the differential pressure to deduce flow rate with an accuracy of $+/-5 \%$. These air flow rate sensors are calibrated with an accurate flow hood device for 5 different fan speeds $(3 \mathrm{~V}, 5 \mathrm{~V}, 6.5 \mathrm{~V}, 8 \mathrm{~V}$ and $10 \mathrm{~V})$, showing an RMSE of $1.3 \mathrm{~m}^{3} / \mathrm{h}$ with a maximum error of $6 \%$ compared to the flow hood reading.

The VAV-boxes also contain a pressure difference measurement unit. These measurements show a larger deviation from the reference measurement: $\mathrm{RMSE}_{\mathrm{VAV}}=7.7 \mathrm{~m}^{3} / \mathrm{h}$ with a maximum error of $-22 \%$ for one of the VAV-boxes. This will evidently influence the operation of the lab setup. The VAV-output signal is translated to valve position in order to supply the required information to the pressure reset control logic.

The pressure sensor (First Sensor CTE), provides the signal to control the fan speed, is a $0-10$ mbar pressure transmitter with a maximum error of $0.5 \%$.

Voltage is measured using analog input terminals with an accuracy of $0.3 \%$ [12] and voltage control signals are sent using analog output terminals [13] with an output error smaller than $0.1 \%$. Fan electrical energy use is measured with a 3-phase power measurement terminal [14] having a $1 \%$ error on the calculated values.

\subsection{Ventilation system Modelica model setup}

A simulation model of this DCV system is created in a MODELICA environment (Dymola) as shown in Fig. 6, by using the Modelica standard library and the IDEAS library [15]. The ventilation model is a dynamic aeraulic model, consisting of: a) a fan model with an rpm control signal y as input; b) a VAV-valve model, including valve, PI-controller with air flow rate as set point and flow rate sensor; c) pressure based duct and junction models, d) air flow rate and pressure sensors and e) a room model to define the $\mathrm{CO}_{2}$ concentration based on occupancy (not present in the lab setup)

Fan, VAV-valves, fittings, bends, flow meters and duct sizes of the lab setup are exactly reproduced in the Modelica model.

\subsection{Fan and VAV-valves}

Fig. 7 shows the operation curve of the fan that is used in the model and lab setup. It is an axial fan with a measured maximum efficiency of approximately $35 \%$ around $400 \mathrm{~m}^{3} / \mathrm{h}$.
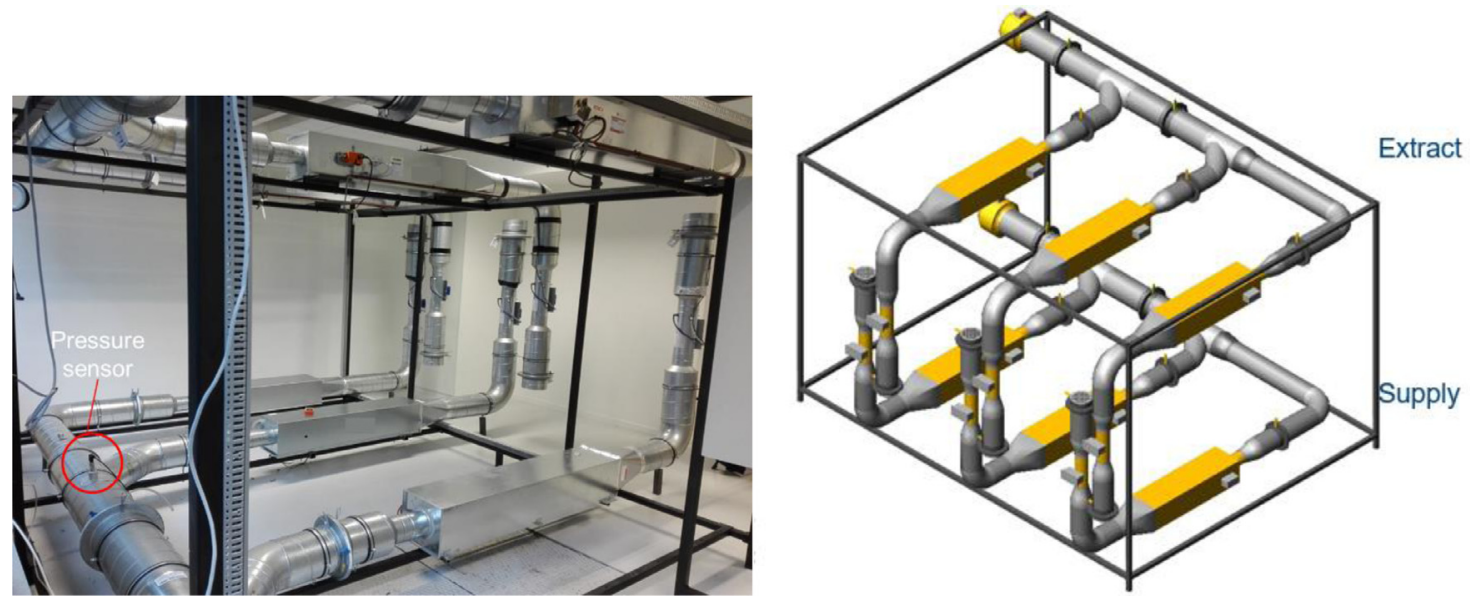

Fig. 5. Picture and 3D view of the ventilation system lab setup (only supply is used in this study). 


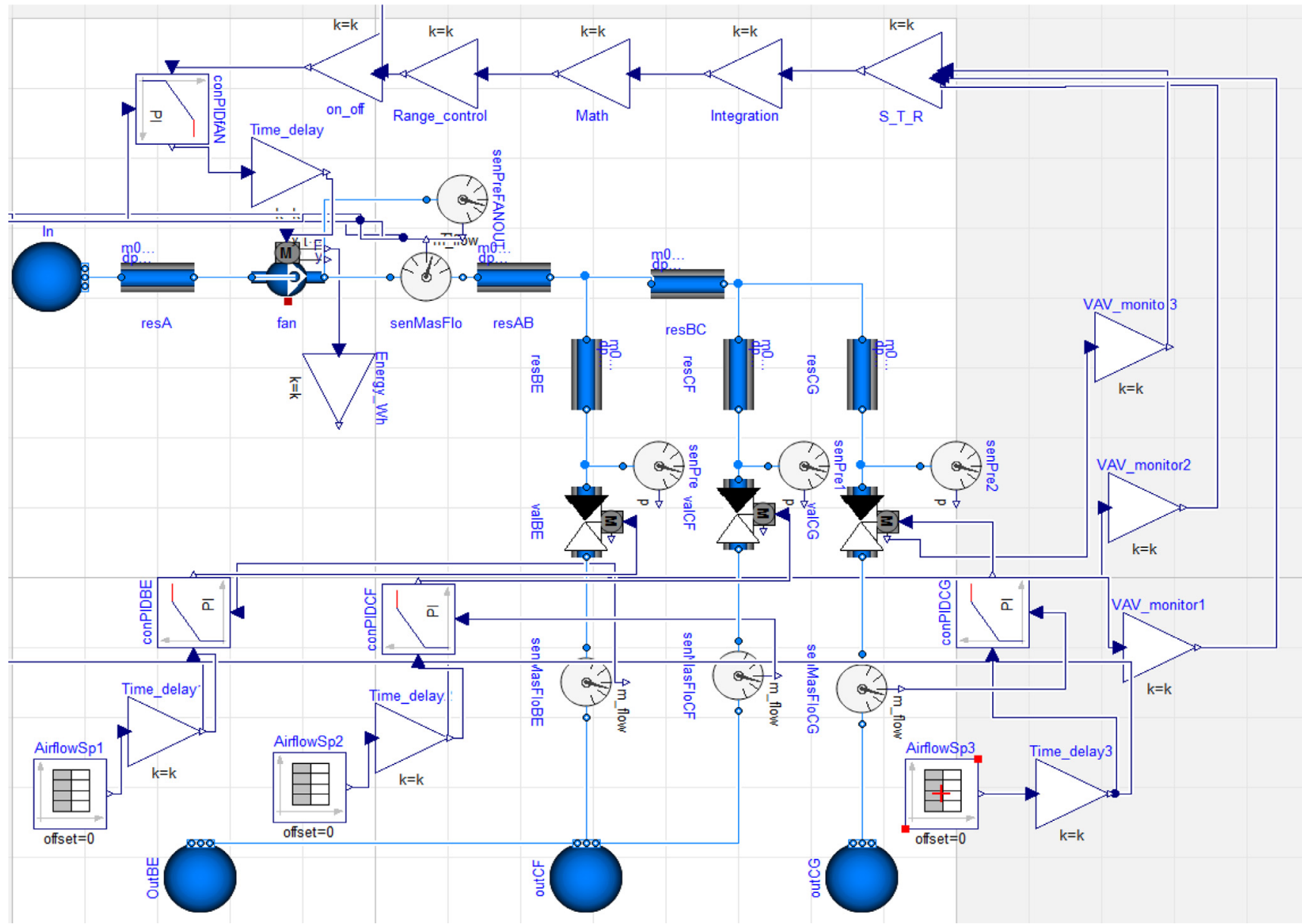

Fig. 6. Modelica ventilation system model.

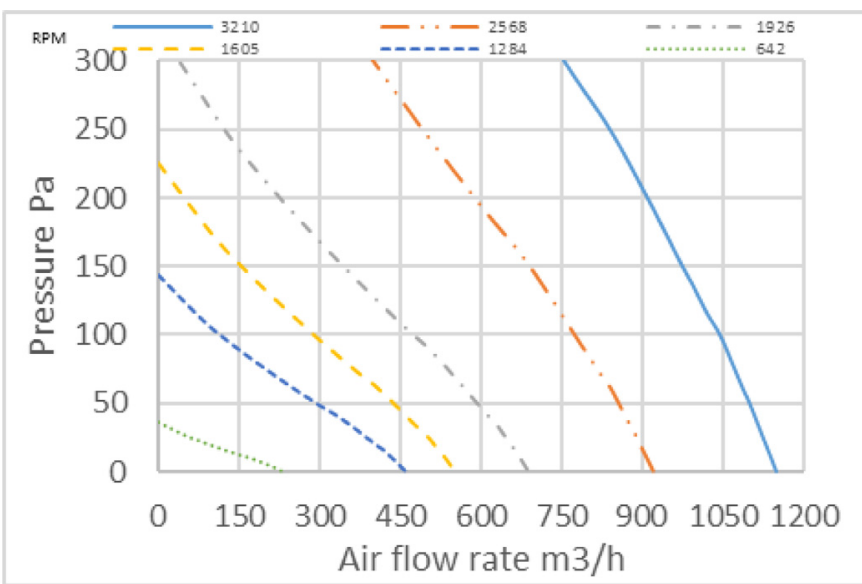

Fig. 7. Fan flow rate-pressure head diagram.

The VAV-valve characteristics differ between the reproduced valve simulation model and the real valves (see Fig. 8). The valve in the simulation model has an equal percentage characteristic, while in the test setup the valve is a 'quick opening' type. Moreover, the valve opening or closing speed are higher in the simulation model than in the lab setup. Because of its impact on the results, this difference in speed is kept and discussed in the results section.

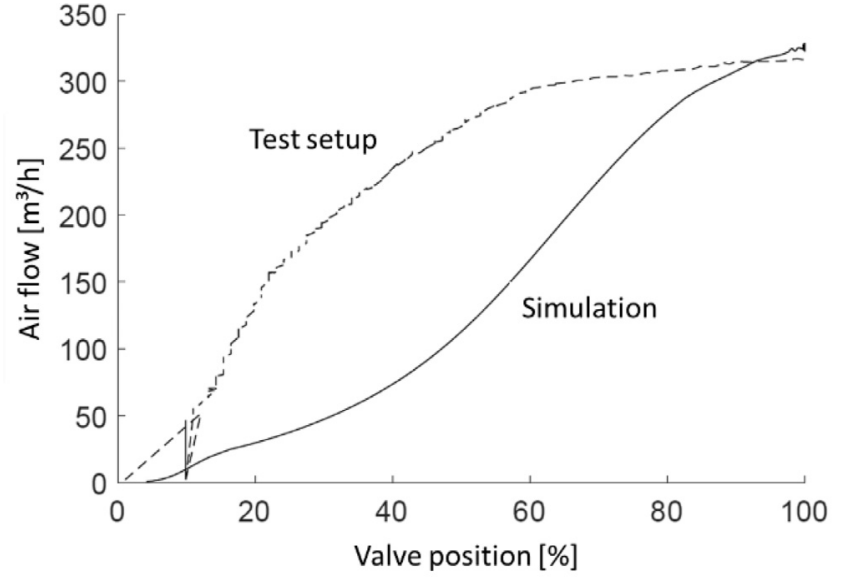

Fig. 8. VAV-Valve characteristics in the simulation model and for the real valves (measured).

\subsection{Air flow rate profiles}

Two sets of 3 air flow rate profiles, each for one office zone, are applied:

- Set 1 with nominal occupancy presence

- Set 2 with $50 \%$ occupant presence 


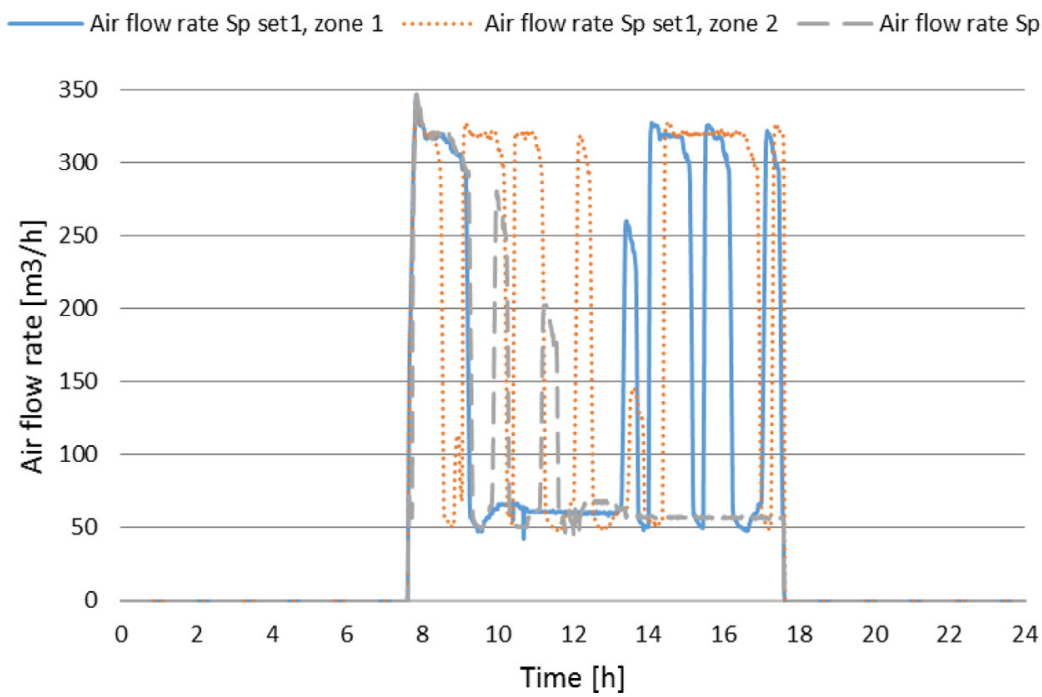

Fig. 9. Air flow rate profiles set 1 for (three zones office as shown in Fig. 4).

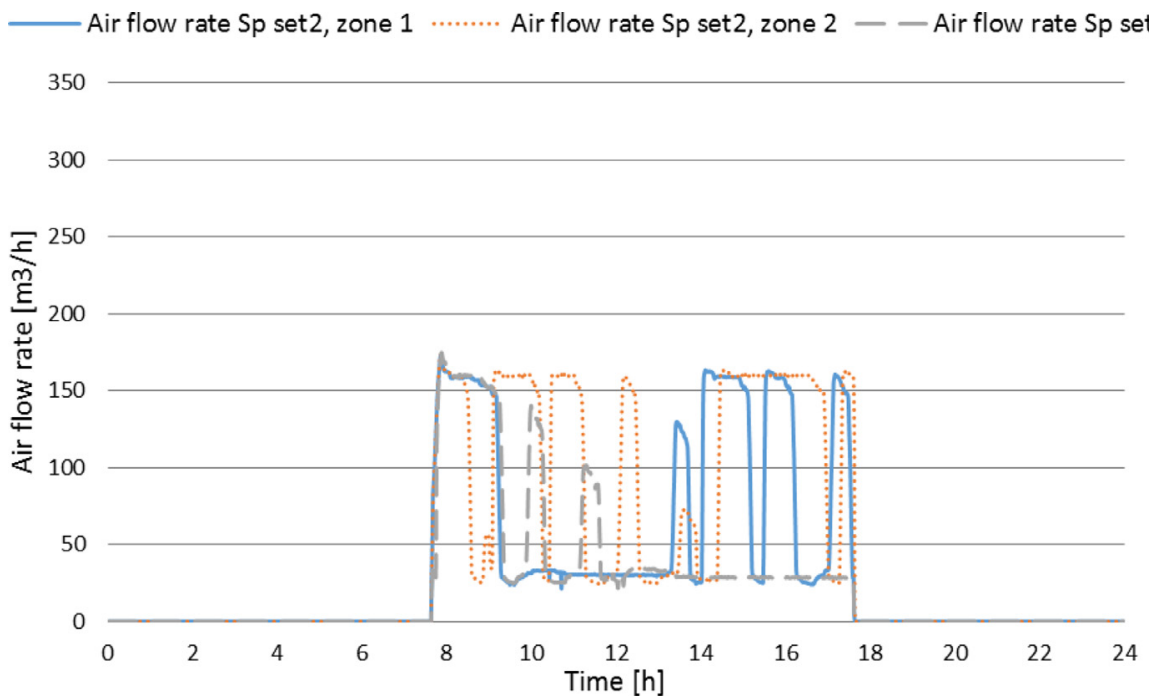

Fig. 10. Air flow rate profiles set 2 for (three zones office as shown in Fig. 4).

The required air flow rate profiles, used as input set point values for the controller, are derived from $24 \mathrm{~h}$ measurements in 3 landscaped offices in a real building in normal conditions [16].

Fig. 9 shows the air flow rate profiles set 1 for the 3 zones during $24 \mathrm{~h}$. This period was chosen because it shows the daily occupancy behaviour of a landscaped office. These values are used as set point for VAV-valves in both Modelica model and lab setup.

Air flow rate profiles set 2 has the same course as set 1 but the air flow rates are divided by 2 to represent a situation when for example half of the employees are not present, as shown in Fig. 10.

Air flow rate profiles set 2 is included in the analysis to evaluate the operation of the ventilation system in low-flow conditions, at the lower limit of e.g. VAV-valve operation range.

The total required volume of air during the observed $24 \mathrm{~h}$ period is $\mathrm{V}_{1}=4916 \mathrm{~m}^{3}$ and $\mathrm{V}_{2}=2458 \mathrm{~m}^{3}$ for respectively air flow rate profile set 1 and set 2 .

\subsection{Static pressure reset implementation approaches}

There are many methods to implement static pressure reset principle. In this paper, a 'Trim and Respond' approach [7,17] based on VAV-valve position will be applied.
Fig. 11 explains the adopted 'Steps Trim and Respond', with VAV-valve positions measured at time $t$. When at least one VAVvalve (most critical VAV-valve) opens between $75 \%$ to $85 \%$, one request is generated. Between $85 \%$ to $95 \%$ two requests are generated and finally when the valve position becomes more than $95 \%$ ten requests are generated.

Once all VAV-valves close between $55 \%$ to $65 \%$ one negative request is generated. Between $45 \%$ to $55 \%$, two negative requests are generated and between $15 \%$ to $45 \%$ three negative requests are generated. Finally when all VAV-valve are less than $15 \%$ open, four negative request are generated. between $65 \%$ and $75 \%$, no requests are generated.

The positive requests will increase the static pressure set point with $y 1 \mathrm{~Pa}$ (pressure increase increment), while the negative requests will decrease the static pressure set point with y2 Pa (pressure decrease increment). This VAV-valve check loop occurs every $4 \mathrm{~min}$.

The maxium static pressure set point should not exceed the design static pressure set point based on full load conditions while the minimum static pressure set is defined by the lower pressure differential limit of the VAV-valve [7]. In this study, this minimum 


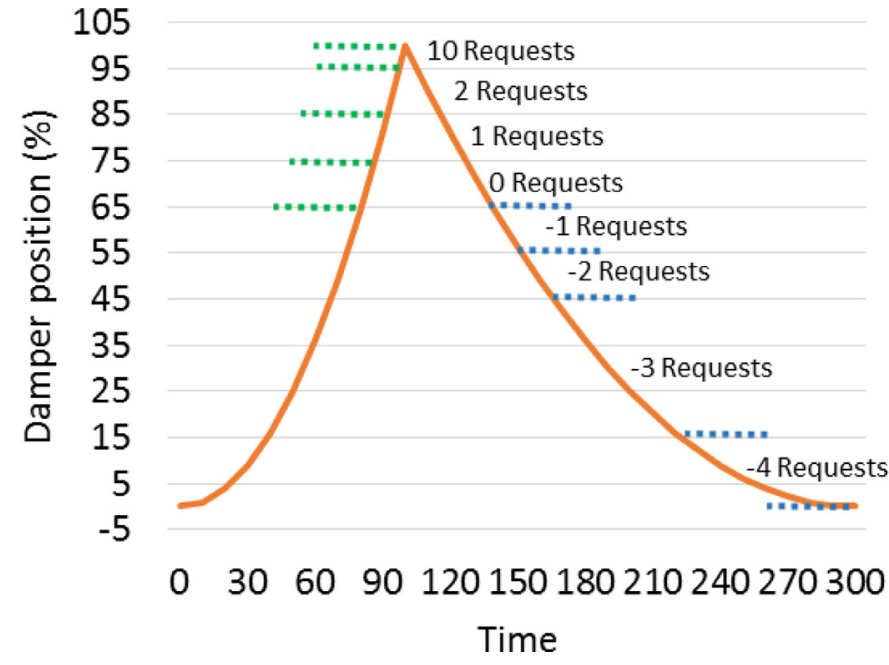

Fig. 11. Steps Trim and respond based on damper position logic.

Table 1

Control parameters for different VPSP control strategy implementations.

\begin{tabular}{lll}
\hline Control method & y1 [Pa] & y2 [Pa] \\
\hline 0 - CAV & - & - \\
1-CPSP & - & - \\
2-VPSP1 & 2 & -1 \\
3-VPSP2 & 3 & -1 \\
4-VPSP3 & 4 & -1 \\
5-VPSP4 & 5 & -2 \\
\hline
\end{tabular}

value is set to $20 \mathrm{~Pa}$ based on manufacturer requirements and the air duct system layout.

\subsection{Implemented control strategies}

Following three control strategies are applied in both Modelica model and lab setup:

1. CAV: constant air volume.

2. DCV-CPSP: demand controlled ventilation with constant static pressure set point

3. DCV-VPSP: demand controlled ventilation with variable static pressure set point

The performance of each control strategy is evaluated on one hand by looking at its ability to supply the required air flow rate and on the other hand by evaluating the fan electricity use.

First, as a reference, a CAV system is modelled. Second, in the constant static pressure set point (CPSP) control strategy, the fan static pressure set point is constant and derived from the duct system design calculation.

Third, in the variable static pressure set point (VPSP) control strategy, the VAV-valve positions are monitored. When all VAVvalves are closing (e.g.in position $U \%$ or lower, note that an open valve has position $=100 \%$ ), the fan static pressure set point will be reduced with y2 Pa. Reversely, when at least one VAV is open in position $\mathrm{W} \%$, the fan static pressure set point is increased with $\mathrm{y} 1$ $\mathrm{Pa}$. After $\mathrm{t}$ minutes, the VAV-valve positions are checked again and the static pressure set point will be in- or decreased whenever required.

For VPSP control strategy, 4 different (y1, y2) combinations are investigated. Table 1 presents the control parameters of VPSP control strategy as used in the simulations, at which point y1 represents pressure increase, y2 represents pressure decrease, every cycle is $4 \mathrm{~min}$.

\subsection{Energy and ventilation performance}

To demonstrate the potential of these approaches, the energy performance of the system is described as "fan electrical energy", versus "air flow rate deficit" (AFD). The fan electrical energy use is based on the fan head and efficiency curves for the simulation runs and on the measured electricity use for the measurements.

Air flow rate deficit (AFD) is expressed in units of 'flow-hour' or $\left(\mathrm{m}^{3} / \mathrm{h}\right) . \mathrm{h}$, in unit $\left[\mathrm{m}^{3}\right]$, at which point an air flow rate deficit of 1 $\left(\mathrm{m}^{3} / \mathrm{h}\right) \mathrm{h}=1 \mathrm{~m}^{3}$, means that during $1 \mathrm{~h}$ the air flow rate was $1 \mathrm{~m}^{3} / \mathrm{h}$ under the required air flow rate set point. Similarly, an 'air flow rate surplus' (AFS) is defined, giving the number of $\mathrm{m}^{3}$ above the set point for the investigated period. A distinction is made between the deficit or surplus at a certain time step $\left(\mathrm{AFD}_{\mathrm{i}} / \mathrm{AFS}_{\mathrm{i}}\right)$ and the deficit or surplus for a full period (AFD/AFS).

$A F D=\sum_{i=1}^{n} A F D_{i}=\sum_{i=1}^{n} \max \left(0,\left(\dot{V}_{s p, i}-\dot{V}_{m, i}\right) \Delta t\right)$

$A F S=\sum_{i=1}^{n} A F S_{i}=\sum_{i=1}^{n} \max \left(0,-\left(\dot{V}_{s p, i}-\dot{V}_{m, i}\right) \Delta t\right)$

With: AFD is air flow rate deficit $\left(\left(\mathrm{m}^{3} / \mathrm{h}\right) \mathrm{h}\right.$, unit), $\mathrm{AFD}_{\mathrm{i}}$ is air flow rate deficit of time step $\mathrm{i}\left(\left(\mathrm{m}^{3} / \mathrm{h}\right) \mathrm{h}\right.$, unit), AFS is air flow rate surplus $\left(\left(\mathrm{m}^{3} / \mathrm{h}\right) \mathrm{h}\right), \mathrm{AFS}_{\mathrm{i}}$ is air flow rate surplus of time step $\mathrm{i}\left(\left(\mathrm{m}^{3} / \mathrm{h}\right) \mathrm{h}\right)$, $\dot{V}_{s p, i}$ is air flow rate set point of time step i $\left(\mathrm{m}^{3} / \mathrm{h}\right), \dot{V}_{m, i}$ is measured (from simulation or measurements) air flow rate of time step $\mathrm{i}\left(\mathrm{m}^{3} / \mathrm{h}\right), \Delta t$ the time step.

Integration of air flow rate deficit or surplus at each time step during the observed period ( $n=24 \mathrm{~h}$ in this case), gives the total air flow rate deficit AFD (expressed in $\mathrm{m}^{3}$ ), and total air flow rate surplus AFS, expressed in $\mathrm{m}^{3}$.

To relate air flow rate deficit value to the total amount of air that was required during this $24 \mathrm{~h}$-period, the relative air flow rate deficit parameter $\mathrm{AFD}_{\mathrm{r}}$ is defined:

$A F D_{r}=100 \frac{A F D}{V}$

With: $A D_{\mathrm{r}}$ is relative air flow rate deficit (\%), AFD is air flow rate deficit $\left(\mathrm{m}^{3}\right)$ and $V=\sum\left(\dot{V}_{s p, i} \Delta t\right)$ is total air volume required according to the set point $\left(\mathrm{m}^{3}\right)$.

\section{Results and discussion analysis}

This section presents simulation and measurement results for the 6 different control strategies listed in Table 1. In addition, the fan performance and energy use are evaluated with the two air flow rate profiles sets.

First, to demonstrate VPSP strategy on fan operation, Fig. 12 shows a snapshot of the fan speed plotted on the fan operation curve for the implemented control strategies.

The black dot refers to the fan speed using a CAV system, the red square refers to the fan speed using the DCV-CPSP strategy and the red square-green star trajectory refers to the fan speed using the variable pressure set point control (VPSP1) strategy. At moment " $\mathrm{t}$ " the required air flow rate is $173 \mathrm{~m}^{3} / \mathrm{h}$. CAV runs on maximum speed at $3210 \mathrm{rpm}$, at which point the fan produces the designed static pressure and air flow rate. CPSP runs on speed at $1600 \mathrm{rpm}$ while the fan produces the designed static pressure and required air flow rate. VPSP1 runs on a lower speed than both CAV and CPSP, i.e. at $1250 \mathrm{rpm}$ while the fan produces a static pressure lower than the designed static pressure.

The VAV-valve positions and pressure set points at time " $\mathrm{t}$ " change by using different control strategies. Using CPSP, the VAVvalve positions are consecutively at time " $\mathrm{t}$ " $(6.5 \%, 2 \%, 2.2 \%)$, while using VSPS the VAV-valve positions open consecutively at time " $\mathrm{t}$ " 


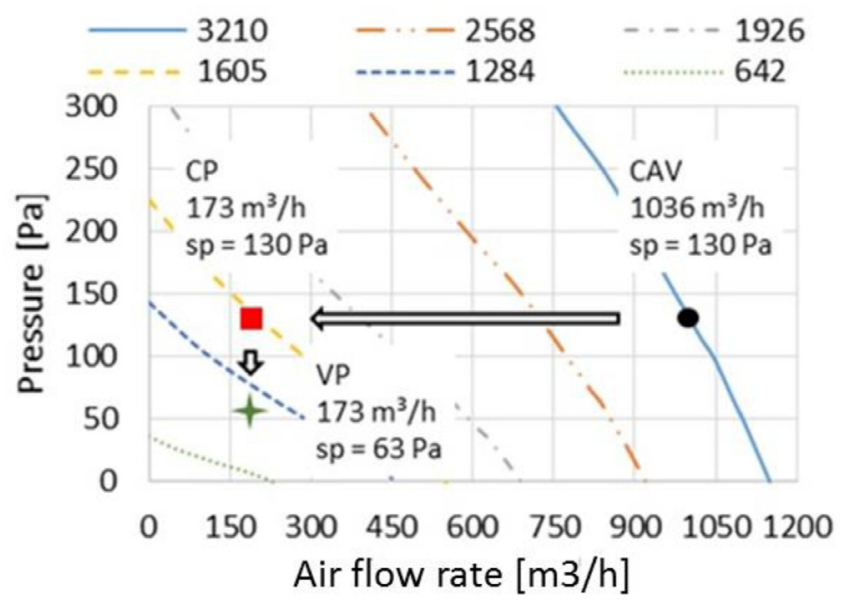

Fig. 12. (Simulation) Fan speed of different control methods at time t.

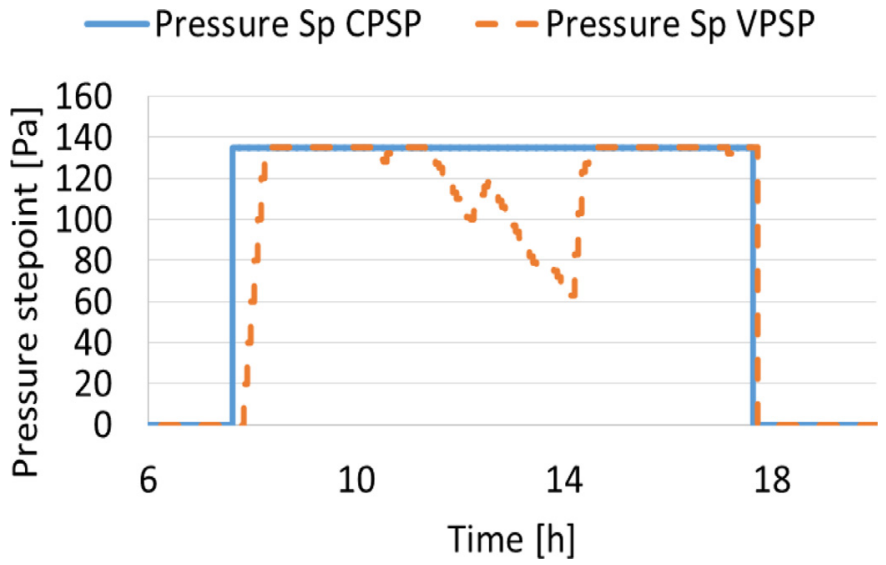

Fig. 13. (Simulation) Static pressure set point during $24 \mathrm{~h}$ for CPSP- (solid line), VPSP1- (dashed line) strategies.

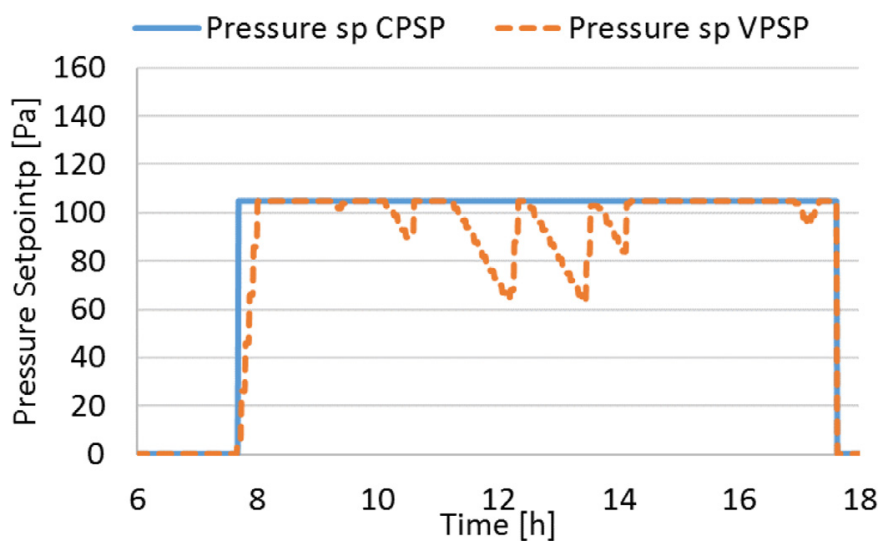

Fig. 14. (Measurement) Static pressure set point for CPSP- (solid line), VPSP1- (dash line) strategies.

$(15.6 \%, 14.7 \%, 14.8 \%)$ to maintain the same air flow rate with the new static pressure set point.m3

\subsection{Variable pressure set point (VPSP) control behaviour}

Figs. 13 and 14 show the fan static pressure set point in both simulations and measurements for CPSP andVPSP1 during $24 \mathrm{~h}$.

In the lab test case, the pressure sensor is located at $2 / 3$ distance of the main line as seen in Fig. 5. Therefore, the maximum pressure set point is the designed static pressure set point

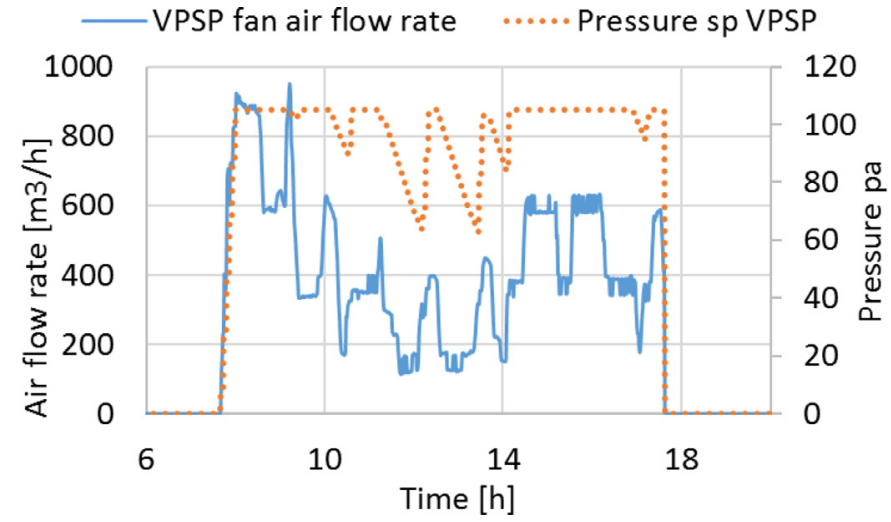

Fig. 15. (Measurement) Generated air flow rate (solid line) and static pressure set point (dashed line) Fan performance analysis.

minus static pressure losses before the sensor (i.e. P_design P_losses $=135-25=110 \mathrm{~Pa}$ ), while in the simulations the pressure sensor is located directly after the fan outlet, therefore the maximum static pressure set point is the designed static pressure set point of $135 \mathrm{~Pa}$.

Figs. 13 and 14 show the static pressure set points, which are associated with VPSP controller, are more oscillating in the measurement results than in the simulation results. The reason for this is than in the simulation case, some conditions are considered ideal. For instances, the VAV-value opening/closing speed, ignoring the turbulence flow in some parts of the duct system.

To demonstrate VPSP1 control behaviour, Fig. 15 presents air flow rate and VPSP1 static pressure set point. When the air flow rate decreases, correspondingly the static pressure set point decreases gradually (this is the 'trim'-action). Once the air flow rate increases, the static pressure set point increases gradually but faster than the decrease (this is the 'respond'-action).

The 'trim'-action is limited to the minimum required pressure to operate VAV-valve (20 Pa over the valve in the case of the VAVvalves installed here).

Based on the lab measurement data on CAV, CPSP and VPSP measurement runs, the fan performance can be analysed. At the nominal speed of $10 \mathrm{~V}$ control signal, the fan operating point is on average $966 \mathrm{~m}^{3} / \mathrm{h}$ and $135 \mathrm{~Pa}$. This means that compared to the theoretical maximal air flow rate, in the lab setup the air flow rate is $7 \%$ lower. The thermodynamic fan efficiency $\eta_{\text {fan }}$ is $21 \%$ at this operating point.

$\eta_{f a n}=\frac{\dot{V} \Delta p}{P_{f a n}}$

With: $\dot{V}$ is air flow rate, $\Delta p$ is pressure rise and $P_{f a n}$ is electrical fan power.

Both Figs. 16 and 17 show measured fan pressure measured fan efficiency point positions on fan performance curve respectively during both CPSP and VPSP1 operation. Moreover, Fig. 16, shows that during operation, the fan VPSP-operating point deviates most from the CPSP in the low flow regions. This means that the VPSPstrategy proves beneficial if the ventilation system frequently operates at reduced flow rate. The efficiency is at its maximum of $\pm 35 \%$ around $400 \mathrm{~m}^{3} / \mathrm{h}$ as shown in Fig. 17.

\subsection{Fan energy use}

Figs. 18 and 19 present the energy use of both simulations and measurements during $24 \mathrm{~h}$ for CAV, CPSP and VPSP1. It shows that in the simulation case CPSP uses 65\% less energy than CAV, while CPSP uses $12 \%$ more energy compared to VPSP1. For lab setup, as 


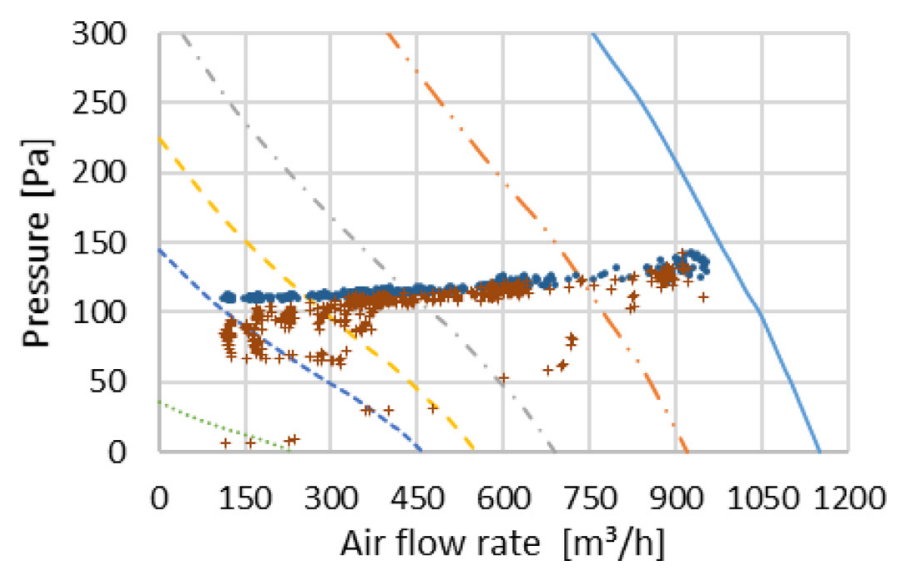

Fig. 16. Measured fan pressure during CPSP operation ('o' blue marker), and VPSP1 operation ('+' brown marker). (For interpretation of the references to colour in this figure legend, the reader is referred to the web version of this article.)

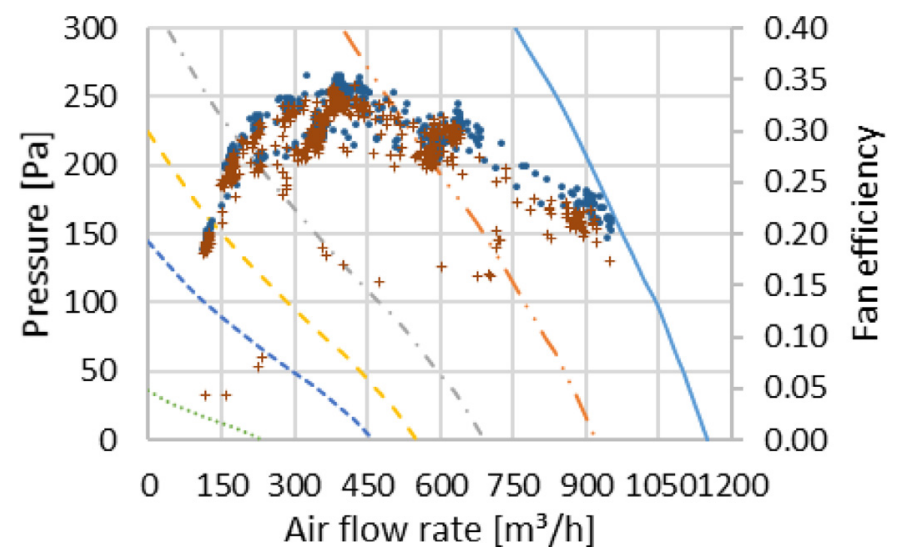

Fig. 17. Measured fan efficiency during CPSP operation ('o' blue marker), and VPSP1 operation ('+' brown marker). Both markers are related only to the right hand fan efficiency axes. (For interpretation of the references to colour in this figure legend, the reader is referred to the web version of this article.)

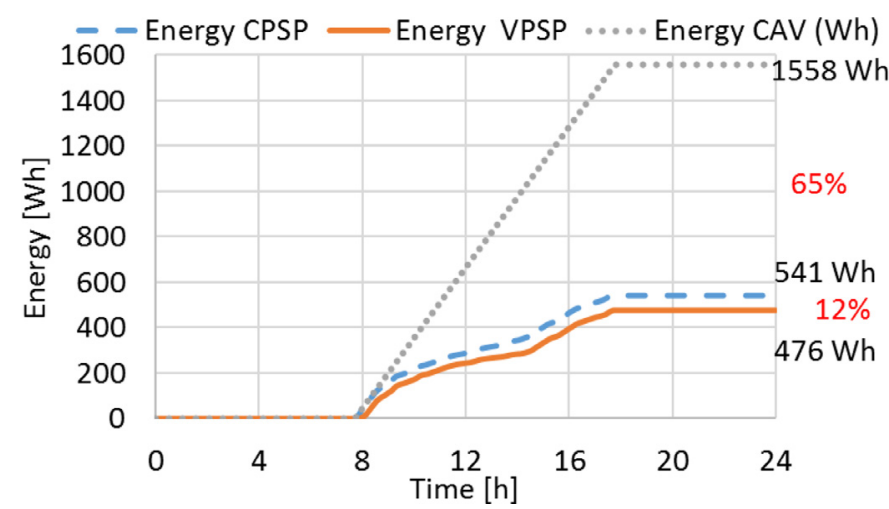

Fig. 18. (Simulation) Energy use during $24 \mathrm{~h}$ for CAV(dotted line), CPSP(solid line), VPSP1(dashed line).

shown in Fig. 19, similar results are obtained. This means that, although the pressure set point variation does not fully coincide between simulation and measurement, the Modelica simulation model is very valuable in predicting the fan energy use, also when variable pressure control strategies are applied.

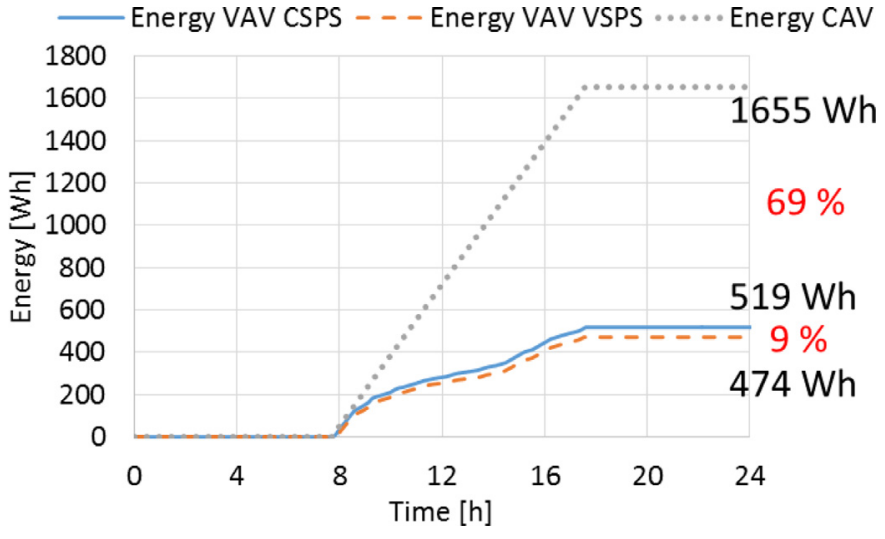

Fig. 19. (Measurement) Energy use during $24 \mathrm{~h}$ for CAV (dotted line), CPSP (solid line), VPSP1 (dashed line).

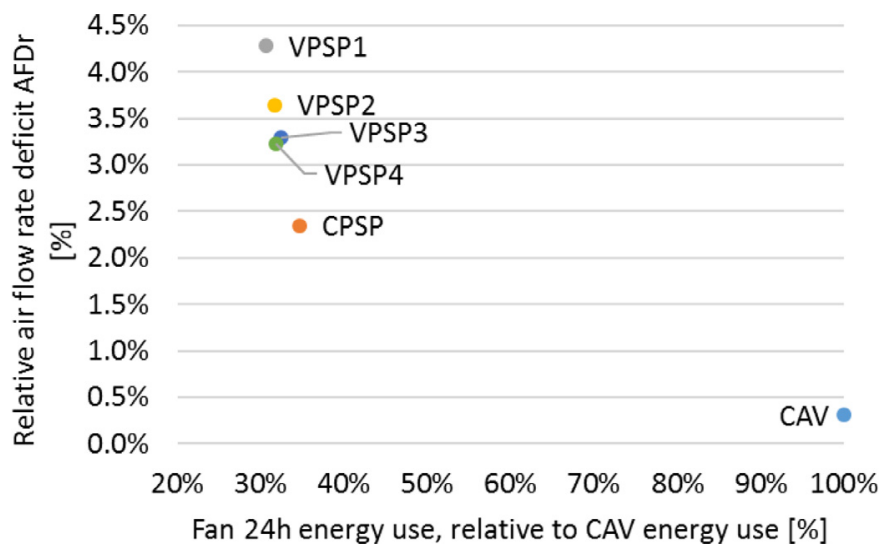

Fig. 20. (Simulation) CAV, CPSP and VPSP relative energy use (compared to CAV) versus relative air flow rate deficit $\mathrm{AFD}_{\mathrm{r}}$.

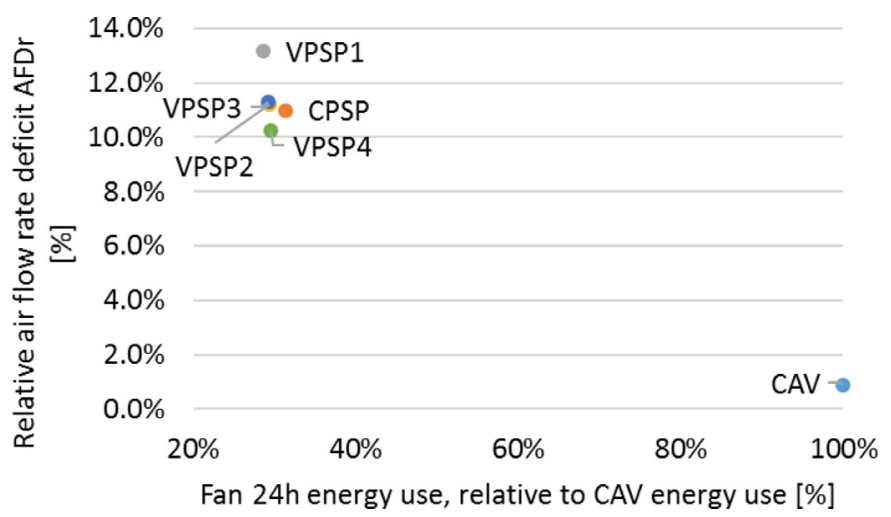

Fig. 21. (Measurement) CAV, CPSP and VPSP relative energy use (compared to CAV) versus relative air flow rate deficit $\mathrm{AFD}_{\mathrm{r}}$.

\subsection{Air flow rate deficit}

Figs. 20 and 21 show the performance results of both simulations and measurements for CPSP and VPSP with different control parameters y1 Pa and y2 Pa. Due to the high constant pressure of CPSP-control, the air flow rate deficit of CPSP is less than VPSP. The air flow rate surplus of all DCV systems coincide (AFS $=2.3 \%$ ). For reference, the air flow rate surplus of CAV system is $5240 \mathrm{~m}^{3}$ in the simulation setup, and $4413 \mathrm{~m}^{3}$ in the lab setup, which is respectively $107 \%$ and $90 \%$ of the required air flow rate.

A clear trade-off exists between fan energy use and air flow rate deficit. Setting the suitable parameters for VPSP control can fur- 


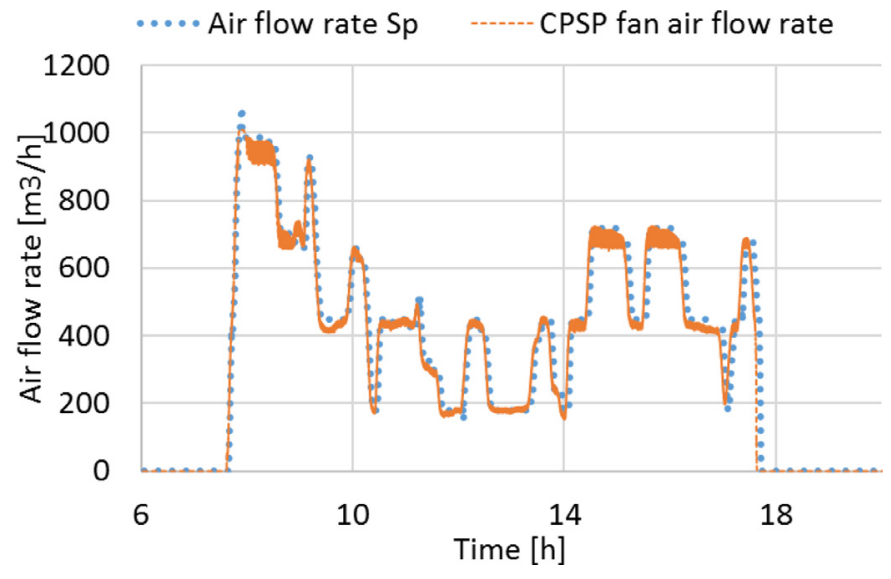

Fig. 22. (Simulation) Air flow rate set point (dotted line) versus CPSP air flow rate (solid line).

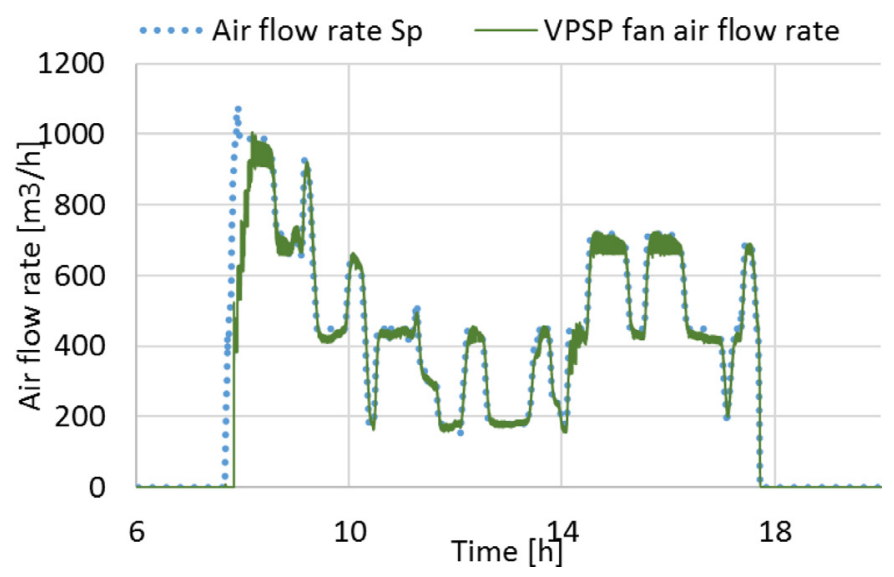

Fig. 23. (Simulation) Air flow rate set point (dotted line) versus VPSP-1 air flow rate (solid line).

\section{- Air flow rate Sp C CPSP fan air flow rate}

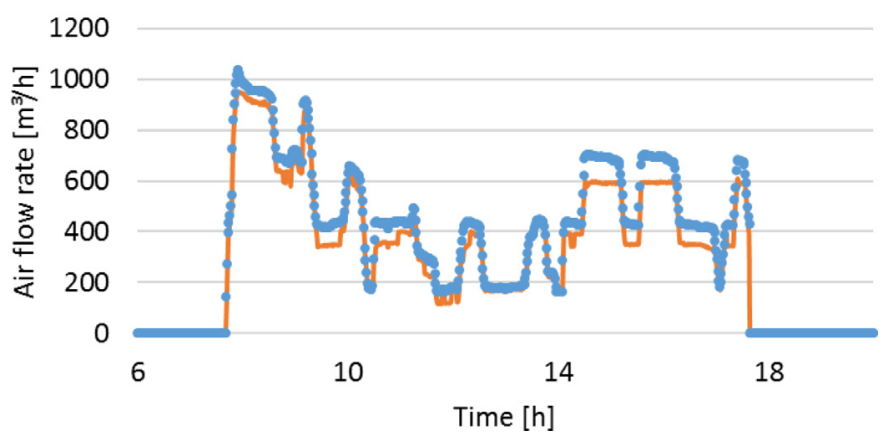

Fig. 24. (Measurement) Air flow rate set point (dotted line) versus CPSP air flow rate (solid line).

ther reduce the energy use. However, due to design deviations and measurement errors, the AFD of VPSP in the measurement setup increases to values larger than $10 \%$, which might affect the indoor air quality in the room.

\subsection{Air flow rate deficit explained}

Figs. 22 and 23 sequentially show the air flow rate set point for both CPSP and VPSP1 in the simulation case. Figs. 24 and 25 show the same parameters for the measurement case.

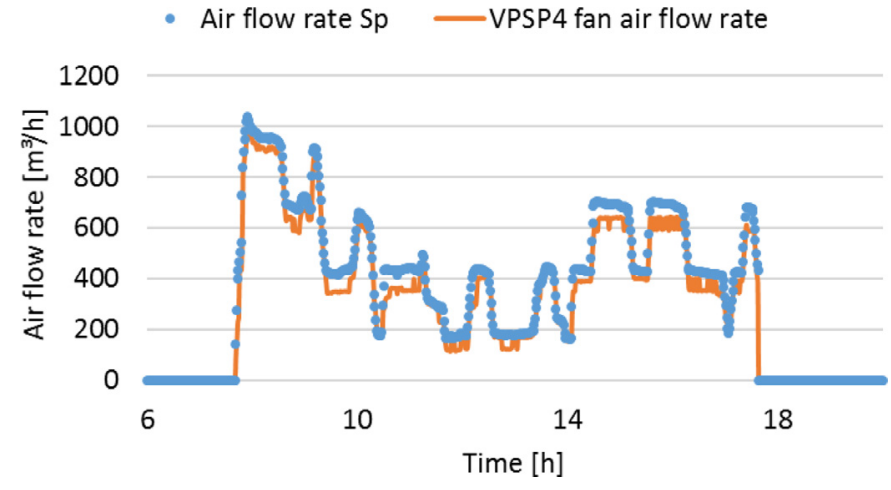

Fig. 25. (Measurement) Air flow rate set point (dotted line) versus VPSP4 air flow rate (solid line).

Table 2

(Simulation) Fan energy use and air flow rate deficit results.

\begin{tabular}{|c|c|c|c|c|c|c|}
\hline & \multicolumn{3}{|c|}{ Fan energy use } & \multicolumn{3}{|c|}{ Air flow rate deficit } \\
\hline & [Wh] & vs CAV & vs CPSP & AFD $\left[\mathrm{m}^{3}\right]$ & AFDr & vs CPSP \\
\hline CAV & 1558 & $100.0 \%$ & & 15 & $0.3 \%$ & \\
\hline CPSP & 541 & $34.7 \%$ & $100.0 \%$ & 115 & $2.3 \%$ & $100.0 \%$ \\
\hline VPSP1 & 477 & $30.6 \%$ & $88.1 \%$ & 211 & $4.3 \%$ & $182.5 \%$ \\
\hline VPSP2 & 494 & $31.7 \%$ & $91.2 \%$ & 179 & $3.6 \%$ & $155.2 \%$ \\
\hline VPSP3 & 505 & $32.4 \%$ & $93.3 \%$ & 162 & $3.3 \%$ & $140.2 \%$ \\
\hline VPSP4 & 497 & $31.9 \%$ & $91.8 \%$ & 159 & $3.2 \%$ & $137.5 \%$ \\
\hline
\end{tabular}

Table 3

(Measurement) Fan energy use and air flow rate deficit results.

\begin{tabular}{|c|c|c|c|c|c|c|}
\hline & \multicolumn{3}{|c|}{ Fan energy use } & \multicolumn{3}{|c|}{ Air flow rate deficit } \\
\hline & [Wh] & vs CAV & vs CPSP & AFD $\left[\mathrm{m}^{3}\right]$ & AFDr & vs CPSP \\
\hline CAV & 1656 & $100 \%$ & & 43 & $0.9 \%$ & \\
\hline CPSP & 519 & $31.3 \%$ & $100.0 \%$ & 539 & $11.0 \%$ & $100.0 \%$ \\
\hline VPSP1 & 474 & $28.6 \%$ & $91.4 \%$ & 645 & $13.2 \%$ & $119.7 \%$ \\
\hline VPSP2 & 487 & $29.4 \%$ & $93.9 \%$ & 550 & $11.2 \%$ & $102.0 \%$ \\
\hline VPSP3 & 484 & $29.2 \%$ & $93.4 \%$ & 555 & $11.3 \%$ & $102.9 \%$ \\
\hline VPSP4 & 489 & $29.5 \%$ & $94.3 \%$ & 503 & $10.3 \%$ & $93.4 \%$ \\
\hline
\end{tabular}

Due to the constant high pressure set point, the CPSP-control is better in following the air flow rate set point than VPSP1-control.

For a step change in air flow rate set point, e.g. at the beginning of the occupancy period $(8 \mathrm{~h})$, VPSP1-control needs some time to increase the static pressure set point from zero to the correct set point, due to the cyclic adaptation of the pressure set point based on VAV-valve positions. This causes the air flow rate deficit that is observed before.

During measurements, at several points in time, the measured air flow rate shows a nearly constant deviation from the air flow rate set point. This is due to the less accurate VAV-box air flow rate measurement (see "Ventilation system lab setup" section) and explains the larger air flow rate deficit in the measurement case. It also shows that the adaptive VPSP strategy is able to counter this error from the VAV boxes, as observable by comparing Figs. 24 and 25. This results in a lower AFD for the VPSP4 strategy, but not for the other VPSP-strategiesr.

\subsection{Energy use versus air flow rate deficit}

Tables 2 and 3 shows the overall system performance by presenting simulation and measurement results of fan energy use against air flow rate deficit. As already shown in Fig. 18, the difference in fan energy use between CAV and CPSP is 65\% and is $12 \%$ between CPSP and VPSP1.

The air flow rate deficit of CAV is very small compared to CPSP, both in simulations and measurements. However, while the AFD of 


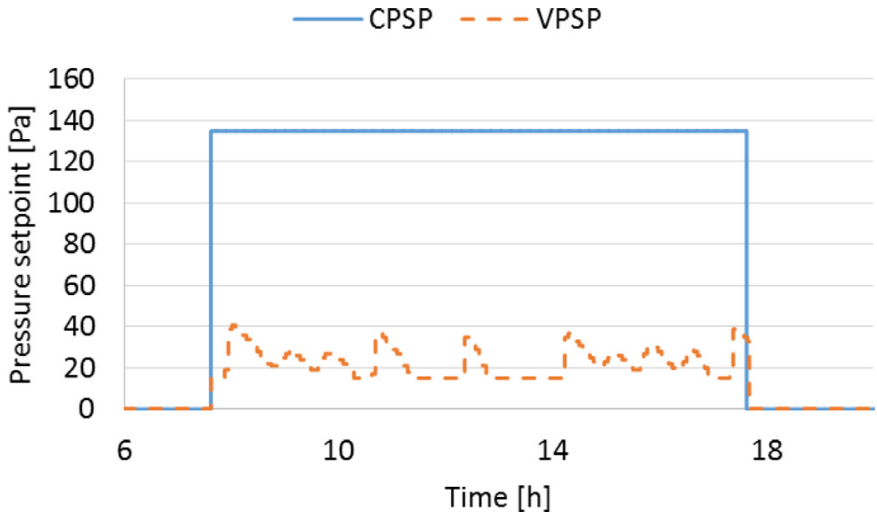

Fig. 26. (Simulation) Static pressure set point for CPSP (solid line) and VPSP1 (dashed line) control strategies.

Table 4

(Simulation) Fan energy use and air flow rate deficit results for air flow rate profile set 2 .

\begin{tabular}{lllllllll}
\hline & \multicolumn{3}{l}{ Fan energy use } & & & \multicolumn{3}{l}{ Air flow rate deficit } \\
\cline { 2 - 3 } & [Wh] & vs CAV & vs CPSP & & AFD $\left[\mathrm{m}^{3}\right]$ & AFDr & vs CPSP \\
\hline CAV & 1558 & $100.0 \%$ & & 15 & $0.3 \%$ & \\
CPSP & 251 & $16.1 \%$ & $100.0 \%$ & & 57 & $2.3 \%$ & $100.0 \%$ \\
VPSP1 & 60 & $3.9 \%$ & $23.9 \%$ & & 101 & $4.9 \%$ & $177.2 \%$ \\
\hline
\end{tabular}

VPSP in simulation is higher than the AFD of CPSP while this is not the case in the measurements. The lower fan performance than assumed based on the data sheets and the VAV measurement errors, create this deviation from the achievable performance as projected by simulation results.

The VAV-valve behaviour explains this difference in AFD between the measurements and the simulations . The 'quick opening' valve characteristic and the smaller opening time create a faster reaction to control signal changes in the lab set up than in the simulation model. Therefore, the deviations from the required air flow rate set point are more quickly compensated in the lab set up compared to the simulation case.

\subsection{Air flow rate profiles set2}

To assess the impact of DCV control in an office that is less densely occupied, or less than designed, the same procedure is applied to air flow rate profiles set 2 . In this case, to reduce the amount of data, only VPSP1 control strategy is presented.

Fig. 26 shows fan static pressure set point for CPSP and VPSP1 during $24 \mathrm{~h}$, during occupancy hours, CPSP keeps the fan static pressure constant with the same value as air flow rate profiles set 1 . Meanwhile VPSP1 changes the fan static pressure based on VAVvalves positions but with values lower than those in air flow rate profiles set 1 .

The impact of applying DCV to low occupied zones is immediately visible. Compared to Fig. 13, the pressure set point of the VPSP control is much lower than in the densely occupied case. This is reflected in the energy saving potential of the VPSP control.

Tables 4 and 5 present both fan energy use and air flow rate deficit results for simulations as well as measurements. The difference in energy use between CPSP and VPSP control strategies is much larger than in the case of air flow rate profiles set 1 , having an occupancy close to the design occupancy. This demonstrates that the impact of VPSP control in offices with a strongly varying occupancy profile, deviating from the design conditions, is significant. In these cases, VPSP control proves its added value. Relative to CAV fan energy use, CPSP and VPSP controls perform almost
Table 5

(Measurement) Fan energy and air flow rate deficit results for air flow rate profile set2.

\begin{tabular}{llllllll}
\hline & \multicolumn{3}{l}{ Fan energy use } & & & \multicolumn{2}{l}{ Air flow rate deficit } \\
\cline { 2 - 3 } \cline { 7 - 8 } \cline { 6 - 8 } & [Wh] & vs CAV & vs CPSP & & AFD $\left[\mathrm{m}^{3}\right]$ & AFDr & vs CPSP \\
\hline CAV & 1655 & $100.0 \%$ & & 7 & $0.3 \%$ & \\
CPSP & 248 & $15.0 \%$ & $100.0 \%$ & & 486 & $19.8 \%$ & $100.0 \%$ \\
VPSP1 & 116 & $7.0 \%$ & $46.8 \%$ & & 494 & $20.1 \%$ & $101.7 \%$ \\
\hline
\end{tabular}

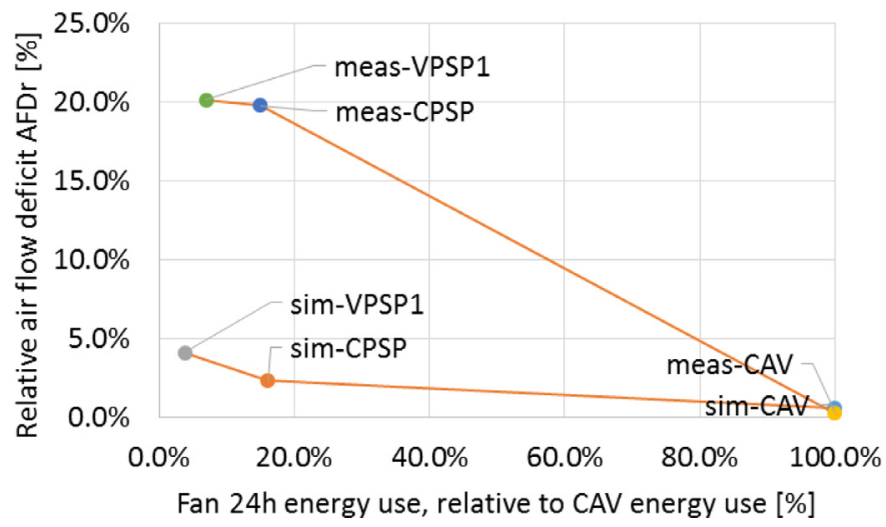

Fig. 27. Fan energy use and air flow rate deficit results for air flow rate profile set2 (simulation and measurement).

equal in both simulations and measurements. However, the fan energy use reduction between CPSP and VPSP is $74 \%$, while it is only $12 \%$ for the air flow rate profiles set 1 . In the measurement case, VPSP reduces the fan energy use with $53 \%$ of compared to CPSP control. This confirms the trend already observed in air flow rate profiles set 1 , where the fan energy reduction of VPSP control is lower in measurements than in simulations. In this air flow rate profile set 2 case, this difference is even more pronounced. and VAV-valve internal control accuracy (pressure difference measurement) explains this observation.

Fig. 27 graphically represents the information contained in Tables 4 and 5 . It shows clearly that ventilation performance is lower in measurement than in simulation, while the fan energy use reduction potential is slightly lower.

Figs. 28(a) and (b), show the difference in ventilation performance between both simulation and measurement that can be explained as follows. It was mentioned before that the VAV-boxes show a measurement error up to $22 \%$ for the air flow rate measurement they perform internally (compared to $6 \%$ for the commercial air flow rate devices). Moreover, they require a minimum differential pressure (20 Pa according to their documentation) over the valve in order to generate a steady feedback signal to their internal controller.

The pressure set point graph in Fig. 29 shows that the fan is able to follow the requested set point accurately. It is also shown that the pressure often reaches a value below $30 \mathrm{~Pa}$. Since this is the pressure in the main duct at position $c$, as showed above in Fig. 4, this means that the pressure difference over the VAV-box measurement device will be lower than $20 \mathrm{~Pa}$, which is outside the operational domain of VAV-valves (the internal pressure difference measurement cannot be performed with sufficient accuracy). This results in cyclic behaviour of the valves on Fig. 28 which was not encountered in the air flow rate profiles set 1 situation as shown on Figs. 24 and 25. Moreover, in a situation when a very low air flow rate is requested, VAV-valves often close completely (this occurs between $12 \mathrm{~h}$ to $14 \mathrm{~h}$ ). This explains the worse ventilation performance in the lab for the low air flow rate profiles set 2 , 

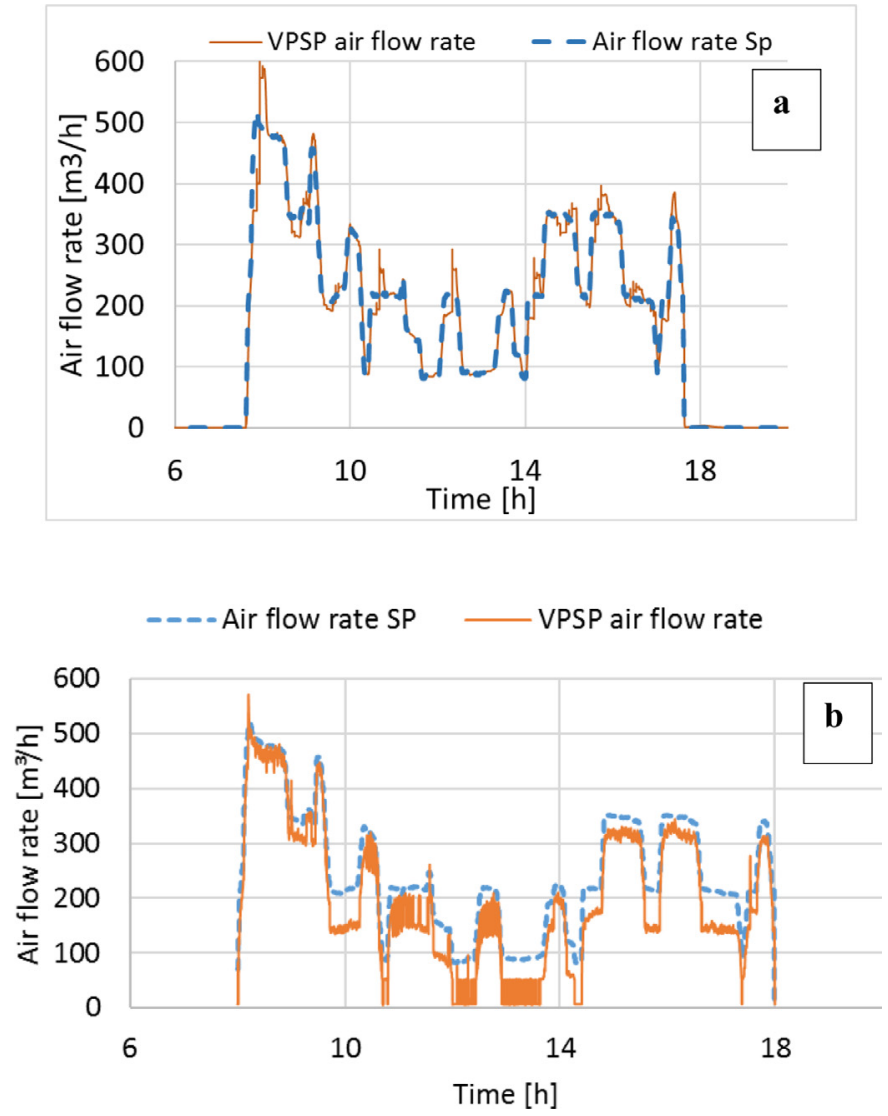

Fig. 28. Provided Air flow rate versus air flow rate set point in VPSP control strategy (a: simulation, b: measurement).

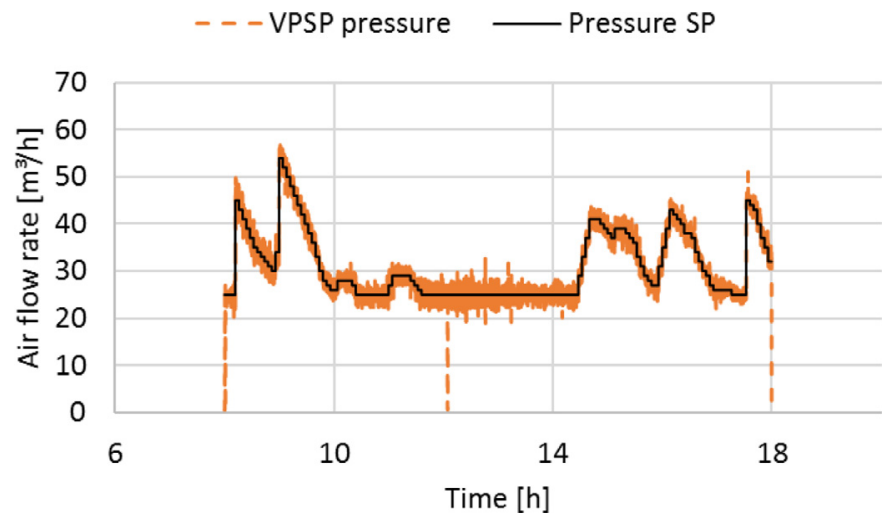

Fig. 29. (Measurement) Pressure set point and recorded pressure for VPSP control strategy.

compared to the set 1 profiles. Also, the life time of the valves is expected to decrease due to this cyclic behaviour.

These observations show that the ventilation system designer should be well aware of the lower operational limits of the ventilation system. In order to guarantee a steady operation in all circumstances, for a system which is projected to operate frequently well below its nominal design values, a minimal operational limit should be hard programmed in the control logic.

\section{Conclusions}

This paper investigates the effect of an adapted control strategy on fan energy use and ventilation performance in a demand controlled ventilation (DCV) system. Typically, the static pressure in the main duct of the ventilation system is kept constant. The effect of further reducing of the static pressure set point when all zones require a low air flow rate, is analysed. A lab setup and a simulation model of a 3 zone ventilation system were constructed. One occupancy profile close to nominal design values and one occupancy profile with considerably lower values were assumed. Three different control strategies were compared: constant air volume (CAV), DCV with constant static pressure set point control (CPSP) and DCV with variable pressure set point control (VPSP). The analysis focused on fan energy use and air flow rate deficit (lower reached air flow rate compared to the air flow rate set point).

A Trim-and-Respond implementation of VPSP strategy, when the pressure set point changes gradually based on VAV-valve position, shows a stable system performance even with a lot of air flow rate fluctuations. However, satisfying a sudden step in air flow rate requirement requires more time when using this approach because the static pressure reset algorithm needs multiple iterations to reach the requested set point for large load change.

Both simulations and measurements show that there is a clear trade-off between air flow rate deficit and fan energy use. Results of both simulations and measurements confirm the energy use reduction potential of DCV based on the traditional CPSP control: $64 \%$ to $84 \%$ less fan energy compared to CAV depending on the applied occupancy profile. The advanced VPSP control is able to reduce the fan energy use even further with approximately $10 \%$ in the high occupancy case and more than $50 \%$ in the low occupancy case compared to CPSP control. Moreover, the results clearly show that tuning VPSP control parameters is recommended to obtain a balance between fan energy use reduction and air flow rate deficit.

To conclude, DCV with an advanced VPSP control should be strongly considered, especially in situations when occupancy is often expected to deviate significantly from the nominal design conditions.

However, lab setup results indicate that care should be taken in real implementations. VAV-valve accuracy, characteristics and their lower operational limit hamper the ventilation system in achieving the performance that is predicted by the simulations. while the energy reduction potential of DCV with VPSP is the largest in zones with largely varying occupancy profiles, the deviation of measurement results from simulation results is also the largest in these cases.

\section{Acknowledgements}

The authors acknowledge the financial support by the Flanders Innovation and En- trepreneurship (VLAIO) in the frame of TETRA project 140345 "Optimisation of demand controlled ventilation in nZEB commercial buildings" and IWT-VIS traject SMART GEOTECH which was co-funded by WTCB. Furthermore the EU financial support through the EU-H2020 GEOTECH project is acknowledged.

\section{References}

[1] IEA, EN13799, Commercial buildings energy consumption survey (CBECS), 2012.

[2] N. Brelih, Ventilation rates and IAQ in national regulations, REHVA Eur. HVAC J. 1 (2012) 24-28.

[3] Braun, J.E., K. Mercer, and T. Lawrence. 2003. Evaluation of demand controlled ventilation, heat pump heat recovery and enthalpy exchangers, HL 2003-10.

[4] B.J. Wachenfeldt, M. Mysen, P.G. Schild, Air flow rates and energy saving potential in schools with demand-controlled displacement ventilation, Energy Build. 39 (October (10)) (2007) 1073-1079.

[5] K. Ahmed, J. Kurnitski, P. Sormunen, Demand controlled ventilation indoor climate and energy performance in a high performance building with air flow rate controlled chilled beams, Energy Build. 109 (2015) 115-126.

[6] S.T. Taylor, Increasing efficiency with VAV system static pressure set point reset, ASHRAE J. 49 (2007) 24-32.

[7] J. Murphy, High-performance VAV systems, ASHRAE J. 53 (10) (2011) 18

[8] C.S. Koulani, R.M. Prunescu, C.A. Hviid, S. Terkildsen, Simulation of static pressure reset control in comfort ventilation, in: Proceedings of the 35th AIVC Conference, Air Infiltration and Ventilation Centre, 2014. 
[9] J. Zhang, X. Li, T. Zhao, H. Yu, T. Chen, C. Liu, X. Yang, A review of static pressure reset control in variable air volume air condition system, Procedia Eng. 121 (2015) 1844-1850.

[10] , Modelica and the Modelica Association, 2017. accessed November 6 accessed November 6 https://modelica.org.

[11] P.J. Brooks, Duct design fundamentals, ASHRAE J. 56 (2010) 31

[12] “BECKHOFF New Automation Technology." [Online]. Available: https://www. beckhoff.be/english.asp?ethercat/el3068.htm. [Accessed: 24-Nov-2017].

[13] "BECKHOFF New Automation Technology." [Online]. Available: https://www. beckhoff.be/english.asp?ethercat/el4008.htm. [Accessed: 24-Nov-2017].
[14] “BECKHOFF New Automation Technology." [Online]. Available: https://www. beckhoff.be/english.asp? ethercat/el3068.htm. [Accessed: 24-Nov-2017].

[15] R. Baetens, R. De Coninck, F. Jorissen, D. Picard, L. Helsen, D. Saelens, OPENIDEAS - an open framework for integrated district energy simulations, in: Proceedings of Building Simulation, Hyderabad, India, 2015.

[16] B. Merema, M. Delwati, M. Sourbron, H. Breesch, Demand controlled ventilation (DCV) in school and office buildings: lessons learnt from case studies, Energy Build. 172 (2018) 349-360.

[17] S.T. Taylor, Resetting set points using trim \& respond logic, ASHRAE J. 57 (11) (2015) 52-57 5p 